\title{
RAMÓN DE MESONERO ROMANOS Y EL PANTEÓN DE HOMBRES ILUSTRES
}

Joaquín ÁlVAREz BARRIENTOS

(CSIC) Madrid

Uno de los intereses constantes en la vida de Ramón de Mesonero Romanos fue Madrid. Al acercarse a sus obras sobre la capital se suele aplicar la división que él mismo estableció entre Madrid físico y Madrid moral, dando más valor a la producción costumbrista que dedicó al segundo Madrid, que a lo que ofrece sobre el primero. Por otro lado, su reflexión sobre la ciudad en tanto que espacio vital suele valorarse de forma un tanto sumaria y superficial como una expresión de madrileñismo casticista e historia positivista. Sin embargo, aunque en esas obras pueda haber algo de eso (en realidad, menos de lo que se piensa, y más en sus comentaristas), sus escritos sobre el Madrid histórico y sobre las reformas de la capital responden a motivaciones más hondas, que se insertan en una línea ilustrada, que él conocía bien, de conversión de la capital en emblema nacional.

\section{Raíces ilustradas del Panteón}

El discurso ilustrado y civilizador es el que le anima cuando escribe sobre los cambios que son necesarios para hacer de Madrid una capital a la altura de las grandes ciudades europeas. Y cuando escribe esto, Mesonero, además de continuidad, muestra de una forma implícita la condición de proyecto inacabado, el fracaso que también en este ámbito cosechó la Ilustración. Sin embargo, su propuesta va más allả. En realidad, pedir que se tiraran casas y se abrieran grandes avenidas y plazas, que se establecieran barrios para la población obrera, como indica en El antiguo Madrid, y que en la ciudad hubiera estatuas, fuentes y edifi- 
cios majestuosos, como pide, iba más allá de las meras medidas de salubridad y mejora estética de la ciudad como escaparate del Estado. Había sido el objetivo de arquitectos y urbanistas europeos del siglo XVIII como Blondel, Laugier, Ledoux, Word, Gandy o Villanueva, y de intelectuales españoles como Martín Sarmiento, Francisco Mariano Nifo o Antonio Ponz, quienes, junto a los mejores arquitectos nacionales, se habían propuesto dar una imagen de Madrid como capital del reino, para lo cual había que dotarla de aquellas señales que indicaran grandeza.

Mesonero Romanos, como antes los citados, quiere convertir a Madrid en un monumento que representara a la nación y, en este sentido, como en otros, es heredero de los ilustrados. Sus libros sobre la capital y sus reformas pretenden dar una imagen identitaria nacional desde ella, no sólo mejorar los accesos, su aspecto y salubridad; quiere dar una imagen nacional como parte de un proceso y proyecto similar al que le ocupa casi por las mismas fechas, los años treinta, de conseguir una literatura y un teatro nacionales (Álvarez Barrientos 1994). Todos -Sarmiento, Nifo, Ponz, Mesonero- participan del mito de la «ciudad ideal» y de la consideración moral y didáctica del arte, ya sea escultórico, arquitectónico o literario. Así, los nombres de las calles y las estatuas de personajes célebres en ellas referían un ideal programa de educación de la sociedad, una propuesta de conductas humanas y de valores en los que el mérito propio frente al de la sangre adquiría un papel destacado. La estatua se entendía como un elemento de propaganda y de reforma cívica, además de cómo un homenaje y reconocimiento de la figura esculpida. Por eso, para estos personajes, la ciudad no es sólo un espacio donde se comercia o se malvive, sino que, además de un espacio para la sociabilidad, es lugar educativo gracias a los mensajes que mandan los nombres de las calles, las estatuas que las adornan y los efectos que producen las luces y las sombras de los edificios. Por lo tanto, la ciudad y las casas habían de ser dignas de aquellos que las habitaban, y, en tanto que espacios didácticos, eran también lugares para la memoria.

Uno de los aspectos centrales a la hora de convertir las ciudades en lugares de memoria, como acuñó Pierre Nora (1997, pero también antes Martín Sarmiento), de memoria nacional, era la erección de estatuas y monumentos conmemorativos de hechos de la historia patria. De los primeros en ver esa posibilidad y en proyectar un programa iconográfico que había de dar cuenta de la historia de España y de los hechos destacables de sus monarcas mediante estatuas y relieves, además de mostrarlos al público para que aprendiera y se identificara con ellos, fue Martín Sarmiento (2002), cuando con motivo de la construcción del Palacio Nuevo a partir de 1738 se encargó de la decoración del mismo. Sarmiento entendió el Palacio como un símbolo de la monarquía, pero también como un elemento fundamental en el proceso de identificación de la naciente nación. Tanto es así que en su programa detalla qué personajes y hechos bélicos, religiosos y cultu- 
rales debian representarse en sus paredes, por ser representativos de «las cosas de España». Son hitos que se convertirían, hasta hoy, en símbolos nacionales: el apóstol Santiago, la Virgen del Pilar, el Cid Campeador, don Pelayo, Felipe II, Carlos V, Sagunto, Numancia, la batalla de las Navas de Tolosa, Atahualpa, Lope, Calderón y otros. Sarmiento da forma al imaginario español en un peculiar Panteón nacional que, según su sueño visionario, debía adornar el coronamiento del Palacio y sus muros. Este edificio, que era representación de toda España y que había de construirse con piedras de sus diferentes regiones, era concebido como un «libro en piedra» dotado de significación, comprensible para cuantos se acercaran a él, ya fueran nacionales o extranjeros, cultos o ignorantes, contemporáneos o visitantes futuros.

El Palacio, por tanto, debía significar -más tarde, los arquitectos de la Revolución Francesa hablarán de una «arquitectura parlante»- y ser un símbolo de lo español, y como tal no tenía que estar aislado de la ciudad. Es entendido por Sarmiento como un espacio de sociabilidad por cuyos alrededores se pasea, de modo que sirve para ordenar el espacio urbano, tanto como el espacio imaginario, pues, al levantar el Palacio Nuevo en el mismo lugar donde estaba el Alcázar se confería al lugar un valor mítico e inamovible como centro del Imperio.

Aunque sólo en parte se llevó a cabo este proyecto de Sarmiento, los presupuestos urbanísticos y culturales de los que partía le sobrevivieron. De modo que su criterio de una arquitectura narrativa y emocional, que debía a Vitruvio pero que puso al día gracias al conocimiento de la obra de otros arquitectos, pasaron a personajes como Nifo o Antonio Ponz, si bien éstos olvidaron las referencias barrocas (algunas delirantes) que gustaban al benedictino, y trabajaron en pro de la simplificación y la comodidad como formas de expresión del progreso y de la grandeza, pues ésta para ellos era el resultado de la simplicidad de líneas y del equilibrio del todo con las partes.

Pero tanto uno como otro (y se podrían citar más autores) estaban interesados no solo en que la capital fuera un espacio de representación digno de la monarquía, sino en que mostrara la importancia de la historia de España, mediante el adorno de estatuas y de todo aquello que pudiera hacer referencia a ella, como los nombres de las calles. Nifo no es tan explícito en sus trabajos sobre este campo, aunque sí lo es en aquellos que aluden a la constitución de una historia de la literatura española, pero no queda duda de ello en las páginas que Antonio Ponz dedica a Madrid y que Mesonero Romanos conocía muy bien. El valor educativo que estos autores dan a la escultura y a la arquitectura está en consonancia con la idea de que el arte ha de ser útil (igual que debía serlo la literatura), como ya se señaló. Así, por ejemplo, Nifo criticó los adornos que se habían hecho para la entrada en Madrid de Carlos III, por la misma razón que Sarmiento censuraba los jeroglíficos egipcios: porque el público no entendía el significado de lo expuesto 
(Álvarez Barrientos 2006). Tanto uno como otro, por otra parte, manifestaban la consideración de que el arte había de ser cosa pública, no algo reducido al consumo privado. Y si Nifo rechazaba aquella decoración efímera para conmemorar la entrada del rey en la capital, Ponz abogaba en 1774 por la conveniencia de decorar las calles de la ciudad con estatuas de los más importantes personajes españoles, pues sería un estímulo para que los ciudadanos se interesaran por ellos, es decir, por la historia propia, y se instruyeran, además de que daban «grandiosidad y ornamento» (1789, III, págs. 83). Antonio Ponz esbozaba después los lugares en los que podrían colocarse las estatuas, qué personajes podrían representarse y los efectos que se conseguirían sobre los «inteligentes, curiosos y aun ignorantes» (pág. 85).

Como otros autores de la época, Ponz se refiere a la ciudad empleando la metáfora del cuerpo humano que acuñó Harvey: las avenidas son arterias, las calles venas --lo cual induce la intención de acomodar el espacio a un nivel humano--, pero esa misma metáfora le vuelve de nuevo sobre la moral, pues el adorno, cuidado y urbanización de la ciudad expresa la condición de la misma, de igual modo que el aspecto exterior de un individuo puede dar indicios sobre su condición. La ciudad ha de ser, por tanto, un testimonio cargado de significación ética e histórica, ha de estar para ser paseada y pensada, pues las calles y plazas se llamarían «de Trajano, de Teodosio, de Honorio», los paseos «de Arcadio, de Ataulfo, de Recesvinto» (pág. 87), lo que haría reflexionar sobre esos ejemplos de conducta y moral propuestos a los ciudadanos, que se preguntarían quiénes habían sido esos personajes y que, estimulados por la duda, correrían a educarse $y$, como no podía ser de otro modo, a imitar, si no sus gestas, sí su patriotismo. De manera que, una y otra vez, la decoración, las reformas urbanas, no iban dirigidas solo a hacer de la capital un lugar habitable y salubre, un espacio de representación digno de la monarquía borbónica, sino además y sobre todo un lugar que fuese memoria de la historia, símbolo y en sí mismo conmemoración de ella. Este proyecto se acompañaba de otras manifestaciones tendentes a fijar un contexto de unidad nacional, como la redacción de historias y diccionarios, la creación de museos y la confección de inventarios de los bienes que forman el patrimonio, comienzo de la consideración historicista y monumental respecto de los testimonios del pasado.

Los intelectuales de la Ilustración y del Romanticismo conciliaron la condición magnífica de los palacios, como representación de las monarquias, con el desarrollo de una ciudad habitable y digna. Es cierto que en España esto fue una asignatura pendiente en cuanto a las realizaciones, pero no en cuanto al pensamiento ni en lo referente a la elaboración de proyectos que pensaban la ciudad desde una consideración urbanística total. En el cambio de siglo, arquitectos como Silvestre Pérez, Juan Gómez, Jorge Durán y otros intentan esa reforma de la 
ciudad proyectando cementerios, hospitales, bibliotecas y demás lugares públicos que fueran cómodos para los ciudadanos, pero las novedades alcanzan también a los diseños de edificios conmemorativos. Con el final del siglo XVIII y la entrada en el XIX, se da en España un interés notable por celebrar a esas figuras de la historia que se estaban convirtiendo en elementos referenciales de la patria, aunque no siempre acompañara la financiación. Así, Leonardo Clemente, por esas fechas, proyecta para Toledo un Panteón, que acoge las aportaciones de la arquitectura de la Revolución Francesa, un Panteón ejemplo de la arquitectura «parlante», y lo mismo sucede con las propuestas de González- Velázquez y de Goya para celebrar en 1812 el 2 de mayo de 1808, y con la pirámide con pórtico que en 1802 diseñó Manuel Laviña como tumba en homenaje a Cervantes, cuyo centenario se cumplía en 1805 (Sambricio 1986, pág. 27; Hernando 2004, pág. 104).

Estas acciones y otras ponen de relieve que existía un buen conocimiento de las corrientes europeas. De modo que no debió de sorprender demasiado la actividad urbanística y celebrativa que proyectó José I en los pocos meses que pudo gobernar, a aquellos que, como Silvestre Pérez (Sambricio 1975), encargado de renovar la imagen de la capital, ya habían iniciado un trabajo en ese sentido. Madrid, a pesar de las actuaciones de Carlos III, seguía siendo una ciudad de perfil esencialmente conventual. Sabida es la política de José I de derribo de conventos y caserío en beneficio de plazas y calles más amplias, que dieran una imagen más digna de la capital. Pero además llevó adelante una política de creación de símbolos nacionales (también urbanísticos) y así, además de intentar una Academia Nacional, dio continuidad a las propuestas de quienes, como Sarmiento, Nifo o Ponz, habían querido establecer un «panteón» de ilustres en los que reconocerse. De este modo, el 20 de diciembre de 1809 decretó la erección del Museo de Pinturas, y durante 1810 dio una serie de decretos que tendían a dotar de imagen a los elementos que habían de representar a la cultura nacional. El 29 de mayo mandaba «colocar en los coliseos del Príncipe y de la Cruz los bustos de varios poetas españoles», como «un monumento en honor de los fundadores de la escena nacional». Se trataba de los bustos de Lope de Vega y de Calderón, de Guillén de Castro y Moreto (José Napoleón 1810, II, págs. 157-158). Todo ello para convertir a Madrid en el centro de la representación nacional.

Pero, además, el 6 de marzo de 1809 había dispuesto que los cuerpos de los reyes, reinas y demás personajes enterrados en los conventos suprimidos de Burgos se trasladasen con sus lápidas y sepulcros a la iglesia metropolitana. Lo mismo había de hacerse en las demás ciudades españolas, que acogerían los monumentos mortuorios en sus catedrales o colegiatas. Este decreto se completó con otro del 21 de junio de 1810 en que se mandaba trasladar a las iglesias principales los restos de los «grandes literatos y artistas». El rey también quiso erigir una estatua a Cervantes en Alcalá de Henares; quería «honrar la memoria de los 
españoles ilustres en letras o de bien acreditada celebridad en las bellas artes, y que los monumentos de su gloria no se pierdan ni olviden» (pág. 174). Estas y otras disposiciones no llegaron a hacerse realidad en su tiempo, pero se recuperaron después. Estamos ante el comienzo de la larga y fracasada historia del Panteón de hombres ilustres españoles.

Otro de los planes centrales para convertir a Madrid en centro conmemorativo y referencial, que aunara los símbolos de la nación, y relacionado con la idea del Panteón, fue hacer del terreno entre el Palacio Real y la iglesia de San Francisco, entonces Salón de Cortes, un espacio político de representación de la realeza, por un lado, y del pueblo, por el otro, proyecto que se recuperaría entrado el siglo XIX y que Fernández de los Ríos (1989, pág. 141) quería vincular en 1868 con las Cortes, mediante la que se llamaría calle Nacional. La idea fue recogida en el decreto de recuperación del Panteón del 31 de mayo de 1869. Este proyecto urbanístico había sido encargado primero a Silvestre Pérez en 1811. Como se sabe, los modelos arquitectónicos y urbanísticos de estos proyectos solían ser la Roma imperial pasada por los principios de la Revolución.

\section{Hombres ilustres y poetas nacionales}

De las colecciones de estampas con las imágenes de los varones ilustres se había pasado a que esas imágenes estuvieran de bulto en las bibliotecas y gabinetes privados, llegando incluso a existir cierta polémica sobre la verosimilitud de las efigies que se mostraban. Estas galerías, ya en el siglo XVIII, se quisieron llevar a lo público, mediante la representación en estatuas de las figuras seleccionadas para formar parte del Panteón nacional, igual que en esa misma época se consolidaron los cánones literarios gracias a la elaboración de los respectivos Parnasos. Un caso educativo y menos caro de galería pública de hombres ilustres es el de las estampas que, desde 1791 y hasta 1820 , se publicaron bajo el título de Retratos de españoles ilustres, que iban acompañadas de un epítome de sus vidas (Carrete Parrondo 1976), y que desde 1807 se pudięron complementar con las Vidas de españoles célebres, de Quintana, que tuvieron muchas ediciones y añadidos.

El siglo XVIII debatió sobre quién debía ser el poeta nacional, lo mismo que el siglo XIX. El debate en principio no se planteó en estos términos, pero los intentos de apropiarse de Lope de Vega y de Calderón de la Barca, por parte de casticistas e ilustrados iban en esta dirección, y son paralelos a los que se conocen para convertir a Shakespeare en poeta nacional inglés, por ejemplo. En España, aunque se eligió a Calderón y se le celebró por todo lo alto, a la larga más parece que acabara ocupando el lugar Cervantes. El descubrimiento del alcalaíno como escritor nacional y universal se da antes y de forma más general que con Calderón 
de la Barca. Las ediciones cuidadas y anotadas de su Quijote dentro y fuera de España comienzan a hacerse en el siglo XVIII y, cuando se acerca la fecha del centenario en 1805 de la publicación de la novela, se plantea dedicarle un monumento conmemorativo, que finalmente sólo queda en el papel. Por el contrario, lo que se hace en 1805 es publicar El Anti-Quijote, de Nicolás Pérez, en el que pasa revista a los errores, descuidos y olvidos de Cervantes. Su proceso de «panteonización», su conversión en poeta nacional, tiene otro hito en el deseo de José I de erigir su estatua en Alcalá. Habrá que esperar, sin embargo, a 1835 para ver la estatua, esta vez en Madrid, frente al Congreso de los Diputados. Mesonero Romanos había pedido en 1833 que se levantara esa estatua y también que se colocara un busto en la casa de la calle de los Francos donde vivió. Más tarde a esa calle se le cambiaría el nombre por el de Miguel de Cervantes. El mismo año 1835, en su «Rápida ojeada sobre el estado de la capital y los medios para mejorarla» escribía: «Vergüenza da [que no haya calles] de Cervantes, de Quevedo, de Lope de Vega, de Moratín, y de otros hombres ilustres que o nacieron o vivieron» en Madrid, ni de Felipe V, Carlos III, Fernando VII, que la hermosearon, ni «de Daoiz y Velarde, de las víctimas del 2 de mayo, que la regaron con su sangre defendiendo la independencia social» (pág. 30).

\section{Panteón de hombres ilustres en 1837}

La estatua de Cervantes tiene importancia porque parece ser la primera que se hace de alguien que ni es militar, ni noble ni pertenece a la familia real, y porque da la impresión de que desencadena algunas acciones, que, seguramente, estaban en el ambiente, con vistas a mostrar la condición civilizada y europea de la capital. Así, al enterarse de que el dueño de la casa en la que vivió el Manco la va a derribar, Mesonero inicia medidas para rescatarla y convertir el edificio en un monumento: su criterio historicista es evidente, así como su conciencia de la necesidad y la conveniencia de fijar elementos representativos de la cultura nacional. Consiguió que Fernando VII se implicara en el asunto y que se levantara la estatua (1994, pág. 446. También Rincón Lazcano 1909, págs. 61-85). Pero esta sensibilidad, que tenía desde algunos años antes, se intensificó como resultado de su viaje de 1833 por Londres y París, durante el que visitó la abadía de Westminster y el Panteón nacional francés. Si bien no le causaron una impresión especial, sobre todo el segundo -como se ve en los posteriores Recuerdos de viaje de Francia y Bélgica (1881, págs. 126-127) y en la «Rápida ojeada» (pág. 34)-, sí considera que en Madrid hace falta una institución similar, por las razones que se han desgranado hasta ahora, pero sobre todo cuando se adentra en la «Isla de los españoles» del cementerio de Pére Lachaisse y ve la cantidad de españoles ilustres enterrados fuera de sus fronteras. De modo que, aunque no 
le gustan las paredes vacías del Panteón francés, ni que no tenga culto, y dado que los más importantes españoles de la historia reciente reposaban en tierras francesas, y considerando además que en España también hubo un tiempo en que se enterró con cierta pompa en las iglesias a los hombres ilustres, considera que podría «conservarse esta idea» y adoptar «un templo (que en Madrid debería ser el de S. Francisco), donde se colocasen las cenizas de los hombres distinguidos, sin suprimir por ello el culto, pues en ningún sitio los cánticos religiosos hablan más al espíritu, que resonando entre las sombras de los varones ilustres, reducidos a la nada del sepulcro» (pág. 37).

Así pues, parece que Mesonero Romanos fue el primero en pedir, después del rey José, la creación de un Panteón, y en sugerir que fuera la iglesia de San Francisco, en tiempos de José I Salón de Cortes, la que lo acogiera, como así será cuando se constituya el Panteón en 1837. Pero su idea no tiene mucho que ver con lo que finalmente sería el Panteón liberal. Mesonero piensa más en figuras «indiscutibles» de la cultura y la historia españolas, cuya relevancia ya había asentado el tiempo, y no tanto en personas más o menos contemporáneas, y sobre todo piensa en un pasado común, cuyos representantes serán ejemplos de moral y patriotismo. El Panteón, para él, era un instrumento conciliador que debía contribuir a fijar la memoria colectiva y una identidad histórica nacional. Si en esto estaba en sintonía con lo que fue el proyecto liberal, lo mismo que en considerar el aspecto educativo del lugar, se distanciaba en casi todo lo demás: por ejemplo, en que se dejara sin culto la iglesia.

La elección de San Francisco respondía a razones de orden ideológico y estético. Por un lado, era uno de los templos y conventos desamortizados; por otro, su estética neoclásica se ajustaba bien a la idea moral de edificio que podía representar a la patria. Al mismo tiempo, San Francisco quedaba cerca del Palacio Real. La iglesia y el convento de los franciscanos habían quedado libres tras la desamortización y el uso al que se la destinaba suponía convertirla en espacio civil y laico, secular, que acogiera los valores del Liberalismo para hacer de ella el centro de la identidad de la nación. Los progresistas hicieron realidad el Panteón por decreto de 6 de noviembre de 1837, dentro de la Ley de Recompensas Nacionales, que estaba pensada para compensar a las víctimas del despotismo fernandino; de esta vinculación se resintió el Panteón. En el artículo 3 de esa ley se destinaba el convento de San Francisco como su sede y se ordenaba trasladar allí los restos de los ilustres que llevaran al menos cincuenta años muertos. Sin embargo, este buen criterio no fue suficiente para dejar a la institución al margen de su utilización política: formaba parte de los proyectos liberales que querían conmemorar a las víctimas de la política absolutista de Fernando VII. Esta es la razón de que, cuando entraran a gobernar los moderados, devolvieran el convento a los franciscanos 
y se olvidaran de una institución que veían hija de la oposición y transmisora de unos valores y de una idea de nación que no se ajustaba a la suya.

Al margen el uso partidista del Panteón, muchos, no sólo los liberales progresistas, entendían que hacía falta tener una institución semejante, pues era señal de progreso, de reconocimiento y agradecimiento a aquellos que habían dado su sangre por la patria o habían aportado algo a su cultura. Era además un medio de promover el patriotismo y de dar imagen de capital, cosa que Madrid no daba a pesar de las reformas emprendidas. Ángel Fernández de los Ríos, tras la revolución de 1868, propuso de nuevo la realización de este Panteón, además de toda una serie de reformas destinadas a convertir la ciudad en una capital moderna capaz de representar a la nación. Especialmente significativo de los intereses que guiaban su obra El futuro Madrid, a este respecto, es la íntima relación que establece entre la reforma política y la urbanística y, en el caso concreto de la representación política, el hecho de que estableciera un triángulo entre el Palacio Real, el Panteón y el Congreso de los Diputados, que quedaría unido al segundo por una calle que habría de llamarse Nacional (1989, págs. 140-141), como ya se adelantó.

El gobierno recuperó la idea del Panteón por decreto del 10 de junio de 1869 y vinculó su inauguración a la ratificación de la nueva Constitución de un modo, nuevamente, nada conciliador. Manuel Ruiz Zorrilla dijo:

España, libre al fin de los poderes opresores que durante tres centurias han dado por premio a nuestros grandes hombres las cadenas, las proscripciones, el tormento, el cadalso, la indiferencia y el olvido; rota ya la tradición absolutista que ha dejado perder los restos de Cervantes, Lope de Vega, Velázquez y tantos otros que todavía en nuestros días entregó al fuego y aventó las cenizas de Padilla, Bravo y Maldonado, tendrá al fin un depósito nacional que atesore y perpetúe lo que hoy se haya disperso, mal conservado y expuesto a desaparecer, un depósito inviolable abierto a la veneración de propios y extraños, que irá enriqueciéndose y completándose a medida que se depuren los nombres célebres, que se investiguen las sepulturas abandonadas, y se busquen en tierra extraña las tumbas de los proscritos (1869, pág. 2493).

Entre aquellos dignos de ser enterrados en él se incluía a muchos de los que Sarmiento había reseñado en su Sistema de adornos: al arcipreste de Hita, a Cervantes, a Luis Vives, a Viriato, a Elcano, al Cid, a Guzmán el Bueno, Gonzalo de Córdoba, Lanuza, al padre Mariana, Cisneros, Quevedo, Arias Montano, Lebrija, Jovellanos, el conde de Aranda, Campomanes, Alonso Cano, Juan de Juanes, Herrera, Villanueva, Ventura Rodríguez, Gracilaso, Ercilla, Calderón, Tirso de Molina, Moreto, Meléndez, Jorge Juan, Gravina y Churruca. Esta vinculación entre Panteón y Constitución serviría para marcar el «carácter regenerador» de la Revolución y para sancionar su «moderación y la grandeza de su triunfo» (Prieto 
y Prieto 1869, pág. 4). Estas mismas consideraciones se encuentran en el folleto Españoles ilustres (1869, pág. 7), que reproduce el decreto de Ruiz Zorrilla del 31 de mayo. En él, además, se presentan las biografías de esos españoles elegidos para este primer traslado, biografías laudatorias y encomiásticas que destacan la lucha por la libertad de los elegidos y reflejan su valor bélico, artístico, etc., lo que sirve para exaltar a la nación frente al mundo, gracias a sus logros y entrega.

Los actos de inauguración del 20 de junio, incluidos Te Deum, cien cañonazos y procesión de varios carros, cada uno de los cuales representaba a uno de los «panteonizados», contaron con el rechazo de la derecha, que entendía el Panteón como una expresión anticatólica y antiespañola, pero tuvieron aceptación popular, a juzgar por lo recogido en la prensa (Boyd 2004, pág. 23). Además de las noticias periodísticas, la Inauguración del Panteón. Programa de la función cívica, describe los carros que habían de formar la comitiva, dónde debía estar situada la sección de artillería ( $\mathrm{P}^{\circ}$ de las Delicias) y otros pormenores como la colocación de las distintas comisiones y el horario que se había de seguir para no estropear el evento. Como era de esperar, el adorno de los carros, de los que el primero es el de España, además de aludir a los individuos que van a ser enterrados en el Panteón, incorpora toda usa serie de símbolos nacionales, desde la bandera a las músicas, pasando por los escudos de todas las provincias, que deben estar en este primer carro, y que es un requisito que recuerda al proyecto de Martín Sarmiento. Además de los elementos que aludían a la actividad de Villanueva, Gravina, Ensenada y otros, en algunos casos sobre los carros iban personalidades. Por ejemplo, Antonio Ferrer del Río, «autor de la Historia de Carlos III» (1869, pág. 5), iba en el del conde de Aranda; Patricio de la Escosura, «ilustrador del Teatro escogido de Calderón» (pág. 6) en el de éste, y en el de Quevedo estuvieron Aureliano Fernández Guerra y Eulogio Florentino Sanz, autor este último de una obra sobre el poeta, como Escosura (2000) había compuesto otra sobre Calderón. El último carro era el de la Fama, con las banderas de las naciones europeas; en determinado lugar del recorrido, había de cantarse «un himno a la patria con numeroso coro» (pág. 12), que recogió Prieto y Prieto (1869). Ya se ve que el despliegue no incorporaba ningún elemento religioso, siendo una exaltación de civilidad y ciudadanía que no gustó a la derecha. Como señala Prieto y Prieto (1869, págs. 12-13), la idea primera era incluir en el Panteón la armería y los museos arqueológico y naval, además de los archivos de incautación, de manera que en él estarían «los hombres, los objetos y muchos documentos en que está cifrada la historia de nuestra existencia como nación».

Pero el Panteón tuvo en contra, además de las fuerzas conservadoras y de la escasa financiación de un proyecto tan caro, otro frente inesperado: aquellas localidades que contaban con muertos ilustres fueron renuentes a exhumar los cuerpos, enviarlos a Madrid y quedarse sin reclamos turísticos ni signos de orgu- 
Ilo patrio local. De este modo, entre diversos intereses y discursos ideológicos, el Panteón se encontró en el centro del debate sobre lo que era España, sobre los modos de entenderla y mostrarla, y sobre el modo de concebir la historia nacional. Todo trabajaba en contra del Panteón. Los franciscanos y los clérigos de la Obra Pía, a quienes había pertenecido San Francisco, insistían en que se les devolviera el edificio, lo que consiguieron en noviembre de ese año. Después, el Panteón pasaba a ser jurisdicción del Ministerio de Estado y a partir de ahí se iniciaba su disolución, restituyendo los cuerpos de los difuntos que habían sido trasladados a sus lugares de origen. San Francisco volvió a tener culto y todo el proceso culminó en 1926 con la vuelta a los franciscanos, por parte de Primo de Rivera, de la propiedad del convento. Se culminaba así el triunfo de la Iglesia y la Monarquía sobre los ideales laicos y democráticos que había representado el Panteón, como señala Boyd (2004, pág. 26), que, en su trabajo, hace la historia del Panteón hasta nuestros días.

Esta historia es la de un fracaso, fracaso arquitectónico, pues la nueva ubicación del Panteón en la basílica de Atocha quedó sin terminar, y fracaso ideológico, por lo que atiende a la incapacidad de crear símbolos y espacios que aunaran a los españoles. Por otro lado, la realidad del Panteón en la época liberal le relaciona con los proyectos que para Madrid quiso el rey José y que, en cierto modo, recuperó e hizo suyos Mesonero Romanos en los años treinta y cuarenta. La centralidad que se daba al lugar donde había de ubicarse da ya señal de la importancia que se le concedía, de su valor como objeto pedagógico, frente a su situación en la basílica de Atocha, a principios del siglo XX un lugar en la periferia y cerrado al público. Siguiendo la concepción ilustrada que concedía a los edificios un valor educativo y moral, además de estético y conmemorativo, el Panteón se entendía como una lección de Historia nacional en la que todos habían de reconocerse, al encontrar en su interior los restos de padres de la patria de todas las tendencias, cosa que no sucedió. Por otro lado, desde que se instaló en la iglesia de Atocha, la Corona lo hizo suyo, y prefirió enterrar sólo a héroes militares. Aunque esto no fue posible y con el tiempo también se colocó allí a políticos como Cánovas, Sagasta y Ríos Rosas, el momento que mostró mejor la distancia entre esa primera intención y aquello en lo que se había convertido se dio en 1911, cuando los restos de Argüelles, Mendizábal, Calatrava, Muñoz Torrero, Martínez de la Rosa y Olózaga, que se encontraban en el mismo mausoleo, fueron trasladados al Panteón, desde el ruinoso cementerio de San Nicolás, donde se encontraban desde 1853. Enterrar en el Panteón de la Corona a los fundadores del liberalismo era más de lo que podía aceptar Alfonso XIII, que denegó el permiso. Sin embargo, el presidente del Congreso, el liberal Romanones, insistió y, como sucedió en 1869 , su traslado quedó engrandecido al coincidir con la celebración del primer aniversario de las Cortes de Cádiz, dando así mayor dimensión al hecho de enterrar en el 
centro de lo que se había querido fuese la representación de la memoria nacional y era un espacio de la monarquía, a claros anticlericales, masones comprometidos con la reducción del poder real (Boyd 2004, pág. 34).

Para esas fechas, 1911, hacía tiempo que Mesonero Romanos había desaparecido, sin embargo, su interés por ese tipo de asuntos lo había heredado su hijo, que dejó para la posteridad dos obras en las que da cuenta del lugar donde se encuentran los enterramientos de importantes figuras de la historia, la cultura y la política española y del traslado de los restos de algunos casi contemporáneos de su padre: Goya, Meléndez Valdés, Moratín y Donoso Cortés (Mesonero Romanos 1899 y 1900$)$.

Ramón de Mesonero Romanos, que siempre se había declarado sospechosamente hombre alejado de la política, había dado numerosos pasos en la cosa pública, guiado por una serie de vectores de carácter práctico y posibilista que a menudo fueron bien acogidos por las instituciones a las que consiguió implicar. Esas acciones reformistas dan cuenta de un plan previo y de un pensamiento cargado de ideología. No es casual, por ejemplo, que quisiera situar en su Antiguo Madrid a los trabajadores en nuevos barrios fuera del casco antiguo de la ciudad (Hernando 2004, pág. 376), y que reservara éste para la burguesía, al tiempo que era contrario a una política de ensanches (Ruiz Palomeque 1976, págs. 133-186). Su actuación pública, que deja ver su condición de hombre conservador pero abierto al debate, marca con claridad una tendencia a la concordia y su rechazo de los revanchismos y las venganzas en que tanto abundó la política nacional del siglo XIX. De ahí las características de su Panteón, propuesto, con ingenuidad idealista e ilustrada, como ejemplo didáctico a las generaciones futuras de unión y colaboración en la construcción de España, una España que, en parte debido a la experiencia de la Guerra y a los exilios, ve y quiere unida, no dispar y separada. Es una visión no muy lejana de la que tradujeron los historiadores del siglo XVIII pero también Modesto Lafuente en su Historia general de España, iniciada en 1850 y que tanto éxito alcanzó.

En 1837 los liberales asumían la propuesta de Mesonero y de José I de elevar un Panteón, y lo hacían en el mismo lugar por él señalado, pero le vaciaban de significado religioso -esencial en su formulación-, y, como se vio, lo vinculaban a una ley de compensaciones. Exaltaban un laicismo que él no compartía y se inclinaban por la «sacralización» de la política y de los modelos liberales. Seguramente, si el Panteón hubiera estado al margen de esa ley y dentro de otro orden jurídico, su uso político no hubiera sido tan habitual. Cada vez que se retome la idea del Panteón, será como parte de una reivindicación del pasado, de un proyecto de cambiar España que quedaba siempre inacabado, y cada vez que se rechace, se justificará del mismo modo, por el propósito de corregir el desvío del camino. La idea de España de liberales y conservadores encontraba en él un 
modo de mostrarse, ya fuera recuperándolo, ya rechazando su existencia, algo que también apoyaba el monarca. Tanto unos como otros, cada vez que alcanzaron el poder, quisieron llevar a cabo un proyecto general frustrado por los cambios políticos, y en ese fluctuar navegó y se hundió el Panteón.

Ejemplo también de esta parcialidad es cómo de una primera idea que acogía a cuantos habían hecho algo por la patria, se pasó a que el Panteón fuera sólo de militares y políticos. Esto llevó a que se creara otro Panteón de Hombres Ilustres integrado sólo por artistas y literatos, que querían reivindicar desde el patriotismo el hecho de haber contribuido también a la grandeza del país. Aunque las gestiones comenzaron antes, hay que esperar a 1900 para que la Asociación de Escritores y Artistas Españoles, que fue la institución promotora de este Panteón, consiga un terreno en la Sacramental del cementerio de San Justo, donado por la Real e Ilustre Archicofradía de San Miguel. E1 24 de mayo de 1902 se exhumaron los restos de Larra,' Espronceda y Rosales y se trasladaron al Museo del Prado, donde quedaron depositados hasta que al día siguiente se inauguró el Panteón y se inhumaron en él. La celebración continuó por la tarde en el Ateneo, institución a la que Mesonero estuvo tan vinculado, y en el acto intervinieron Núñez de Arce, Fernández Jiménez, Sinesio Delgado, Serafín Álvarez Quintero, Silvela, Manuel de Palacio, Moret y Ramos Carrión, además de Carolina Coronado, que envió una poesía leída por el conocido zarzuelero (Porpetta 1986). A Larra y Espronceda les seguirían en este particular Panteón de artistas Leandro Fernández de Moratín, Ramón Gómez de la Serna, Maruchi Fresno, Carmen Conde, Luis Escobar y Rafaela Aparicio, entre otros.

Si este Panteón es a veces frecuentado por curiosos y admiradores, el político, el de Atocha, hoy es un edificio apenas visitado, del que los madrileños no tienen noticias (menos aún el resto del país) y cuya utilidad y razón de ser se desconoce. Es un símbolo también de los fracasos por conjugar y armonizar las diferentes ideas de España como nación. Si se le puede considerar lugar que surgió para evidenciar una memoria nacional, hoy en día más parece recordar esa incapacidad reiterada de los españoles (o de sus políticos) para llegar a acuerdos y concordias, esa insistencia en marcar más lo que distancia y diferencia que aquello que une, y desde luego es manifestación del fracaso del modelo liberal.

'El 13 de febrero de 1901 Larra había recibido en el cementerio de San Nicolás la visita de Baroja, Azorín y otros que entonces le consideraban su progenitor vital y literario. 


\section{BIBLIOGRAFIA}

Álvarez BARrientos, Joaquín, 1994. «Ramón de Mesonero Romanos y el teatro clásico español», Ínsula, 574, págs. 26- 28.

- 2006. «Nifo, civilizador y urbano», en Francisco Mariano Nifo y su tiempo, Alcañiz, Instituto de Estudios Turolenses (en prensa).

Boyd, Carolyn P., 2004. «Un lugar de memoria olvidado: el Panteón de Hombres Ilustres en Madrid», Historia y política, 12, págs. 15- 39.

Carrete Parrondo, Juan, 1976. «Diego Antonio Rejón de Silva y la colección de Retratos de españoles ilustres», Revista de Ideas Estéticas, 135, págs. 211-216.

Escosura, Patricio de la, 2000. Don Pedro Calderón, ed. Joaquín Álvarez Barrientos, Zaragoza, Calderón.

ESPAÑOLES, 1869. Españoles ilustres cuyos restos han de ser trasladados al Panteón Nacional en el solemne dia de su inauguración, 20 de junio de 1869, Madrid, Carlos Frontaura.

FERNÁNDEZ DE LOS Ríos, Ángel, 1989. El futuro Madrid, ed. Antonio Bonet Correa, Barcelona, Los libros de la frontera.

Hernando, Javier, 2004. Arquitectura en España 1770- 1900, Madrid, Cátedra. INAUguración, 1869. Inauguración del Panteón Nacional: Programa de la función civica que ha de celebrarse el domingo 20 de junio de 1869, Madrid, Imp. de T. Fortanet.

José NAPOLEÓN, 1810. Prontuario de las leyes y decretos del rey nuestro señor don ...del año de 1810, II, Madrid, Imprenta Real.

MERCADER RiBA, Juan, 1983. José Bonaparte, rey de España. 1808- 1813. Estructura del estado español bonapartista, Madrid, CSIC.

MESONERO Romanos, Manuel, 1898. Las sepulturas de los hombres ilustres en los cementerios de Madrid, Madrid, Imp. de Hernando y Cía.

- 1900. Goya, Moratín, Meléndez Valdés y Donoso Cortés: Reseña histórica de los anteriores enterramientos y traslaciones de sus restos mortales hasta su inhumación en el mausoleo del cementerio de San Isidro el día Il de mayo de 1900, Madrid, Hijos de M. G. Hernández.

Mesonero Romanos, Ramón, 1881. Recuerdos del viaje por Francia y Bélgica en 1840 a 1841, Madrid, Oficinas de La Ilustración Española y Americana.

- 1989. Rápida ojeada sobre el estado de la capital y los medios de mejorarla, intr. Edward Baker, Madrid, Cidur.

- 1994. Memorias de un setentón, eds. José Escobar y Joaquín Álvarez Barrientos (eds.), Madrid, Castalia.

NORA, Pierre, 1997. Les lieux de mémoire, Paris, Gallimard, 3 vols.

Pastor Mateos, Enrique, 1970. El Panteón de Hombres Ilustres, Madrid, Ayuntamiento. 
PORPETTA, Antonio, 1986. Escritores y artistas españoles: historia de una asociación centenaria, Madrid, Asociación de Escritores y Artistas Españoles.

Prieto y Prieto, Manuel, 1869. Descripción de San Francisco. Decreto de las Cortes constituyentes de 1869 con los apuntes biográficos de los grandes hombres cuyos restos quedan depositados al inaugurarse el Panteón, Madrid, Imp. de T. Fortanet.

RosenAu, Helen, 1999. La ciudad ideal. Su evolución arquitectónica en Europa, Madrid, Alianza.

RinCón LAZCANO, José, 1909. Historia de los monumentos de la Villa de Madrid, Madrid, Imp. Municipal.

Ruiz Palomeque, Eulalia, 1976. Ordenación y transformaciones urbanas del casco antiguo madrileño durante los siglos XIX y XX, Madrid, CSIC.

Ruiz Zorrilla, Manuel, 1869. [Discurso]. Diario de Sesiones de las Cortes Constituyentes, $\mathrm{n}^{\circ} 87,1$ de junio, págs. 2492- 2493.

Sambricio, Carlos, 1975. Silvestre Pérez, arquitecto de la Ilustración, San Sebastián, Colegio de Arquitectos Vasco- Navarro.

- 1986. La arquitectura española de la Ilustración, Madrid, Consejo Superior de los Colegios de Arquitectos de España/ Instituto de Estudios de Administración Local.

SARmiento, Martín, 2002. Sistema de adornos del Palacio Real de Madrid, eds. Joaquín Álvarez Barrientos y Concha Herrero Carretero, Madrid, Sociedad Estatal de Conmemoraciones Culturales. 